\title{
Some facts and thoughts: p73 as a tumor suppressor gene in the network of tumor suppressors
} Lakshmanane Boominathan*

\author{
Address: 49, Nattar main street, Murungapakkam, Pondicherry-4, India \\ Email: Lakshmanane Boominathan* - boominathan.lakshmanane@gmail.com \\ * Corresponding author
}

This article is available from: http://www.molecular-cancer.com/content/6/1/27

(c) 2007 Lakshmanane; licensee BioMed Central Ltd.

This is an Open Access article distributed under the terms of the Creative Commons Attribution License (http://creativecommons.org/licenses/by/2.0), which permits unrestricted use, distribution, and reproduction in any medium, provided the original work is properly cited.

\begin{abstract}
The question of whether $\mathrm{p} 73$ is a tumor suppressor gene, is not yet answered with full confidence. The lack of spontaneous tumor formation in p73 null mice and infrequent p73 mutations seen in a variety of cancers analyzed would straightaway negate its role as a primary tumor suppressor gene. However, accumulating evidence suggest that $p 73$ gene and its target genes are hypermethylated in the cancer of lymphoid origin. Here I discuss some facts and thoughts that support the idea that p73 could still be a tumor suppressor gene. The tumor suppressor network in which p73 appears to be a participant involves E2FI, JunB, INK4a/p16, ARF/p19, p57kip2 and BRCAI. Knock out of each gene in E2F-I-p73-JunB-p I6INK4a network of tumor suppressor proteins result in lymphoma/ leukemia formation. Further, I tried to explain why lymphomas are not seen in p73 null mice and why $\mathrm{p} 73$ gene is not prone to frequent mutation.
\end{abstract}

\section{Background}

p73 is a structural and functional homologue of the tumor suppressor, p53. Knock out studies suggest that p73 null mice do not produce spontaneous tumor formation even after two years. However, it appears that p73 shares the properties of the tumor suppressor $\mathrm{p} 53$. It functions more like its counterpart, p53, when it is overexpressed, it promotes growth inhibition or apoptosis.

\section{Evidence in favor of p73 as a main player in the network of tumor suppressors}

1 . The p73 gene was methylated in $94 \%$ cases of natural killer cell lymphomas, a frequency that is the highest known for any human malignancy[1]. In the NK cell lymphoma line NK92, p73 was also completely methylated(figure 1), and the p73 transcript was correspondingly not detectable by quantitative polymerase chain reaction $[2,3]$. Treatment of the cell line with 5-azacytidine, a demethylation reagent, led to demethylation of the p73 promoter and reinduction of p73 gene expression. These results suggest the following: (a)Promoter CpG methylation might be an important mechanism in suppressing p73 gene expression in NK cells. (b) p73 can be a tumor suppressor in NK cells.

2. Epigenetic silencing mechanism has been shown to attenuate the expression of p73 in lymphoid cells but not in other tumors. p73 mutations seem to be infrequent, but some tumors do show LOH (20-60\%). Interestingly, lymphoid tumors are not prone to LOH[4]. Genomic structure analysis of p73 promoter has found regions enriched in CpG islands, unlike p53 gene promoter. This could be one of the reasons why p73 is more prone to DNA methylation mechanisms, unlike p53. Aberrant methylation of $\mathrm{p} 73$ promoter has been detected in leukemia and lymphoma but not in blood cells(figure 1), sup- 


\section{Normal cell}

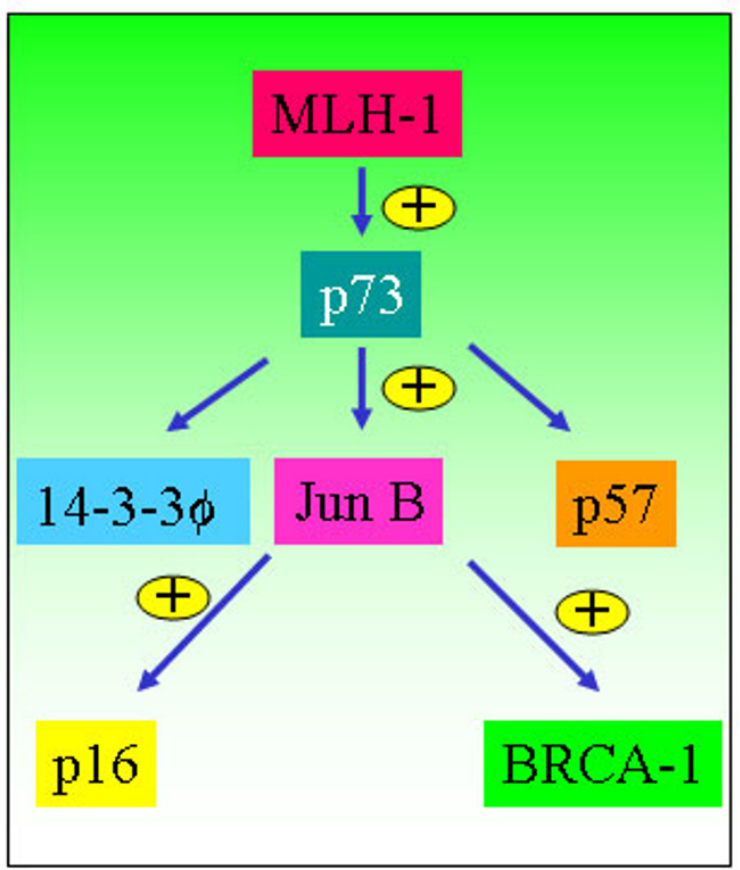

Cancer cell

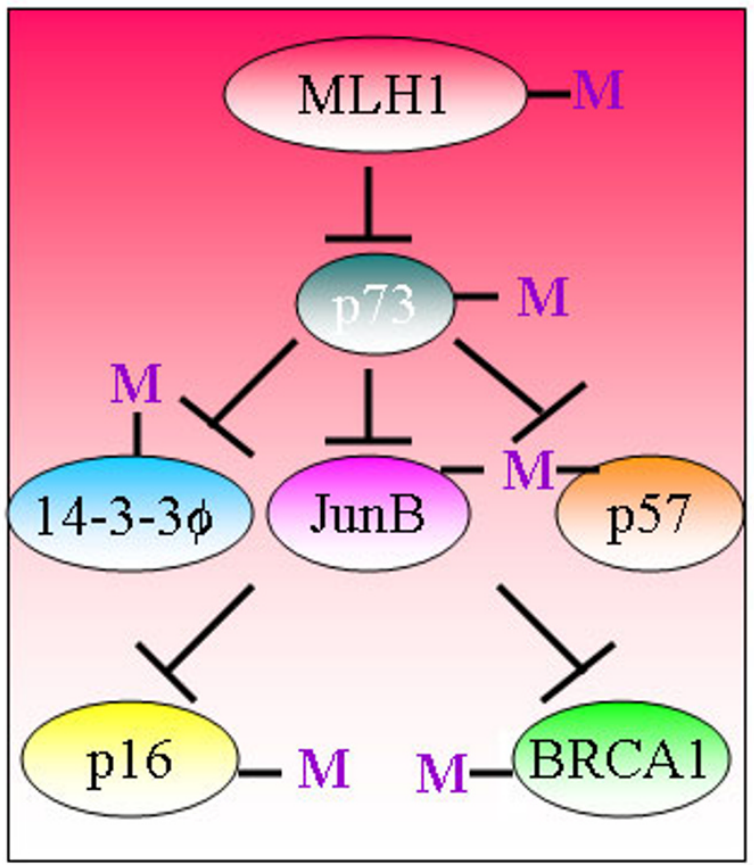

Figure I

Methylation mechanism is evident in cancer cells but not in normal cells.

porting the possibility that appropriate methylation status of the CpG islands in the promoter region may play a crucial role in the downregulation of p73 gene expression. Unlike the p53 gene promoter, the human p73 gene promoter contained a putative TATA-box, and did not exhibit any extended homology to the p53 gene. Two CpG islands were located in the $5^{\prime}$ upstream region. Transient transfection assays using progressive truncations of the p73 promoter showed that deletion from -119 to +19 relative to exon 1 resulted in a 13- to 20-fold reduction in the p73 promoter activity, suggesting that the elements for basal promoter activity exist in this region, where in putative Sp1, AP-2 and Egr-1, 2, 3 sites are located and CpG dinucleotides are especially concentrated[5].

3. It has been shown recently that promoter methylation of at least one tumor suppressor gene was present in 26/
$28(92 \%)$ of the intraductal papillary mucinous neoplasms (IPMNs)[6]. The cell cycle control genes, p16 and p73, were methylated frequently $(>50 \%)$ in both noninvasive and invasive tumors[7]. Pancreatic cancer is particularly resistant to apoptosis induced by antineoplastic agents, which is partly attributable to the lack of functional p53. However, it has been shown that E2F1 in combination with the most clinically efficient drug, gemcitabine, resulted in a strong induction of apoptosis independent of functional p53, whereas the effect of either therapy alone varied between different cell lines. Intratumoral injection of a helper-dependent adenovirus vector expressing E2F1 plus drug treatment resulted in a significant reduction of tumor volume[6]. The therapeutic effect is directly correlated with the induction of the p53 homologue p73, suggesting that the recently discovered $\mathrm{E} 2 \mathrm{~F} 1 / \mathrm{p} 73$ pathway plays a critical role in cancer therapy. 
4. The fact that $M L H-/$ - fibroblasts do not induce $\mathrm{p} 73$ in response to cisplatin treatment indicate that MLH-1 is upstream to p73 and it is a participant in the DNA repair pathway $[8,9]$. MLH-1 has been shown to be hypermethylated in several tumors including gastric and hemotopoietic origin. If MLH is an upstream regulator of p73 in tumors (in which MLH is hypermethylated), then p73 may not be activated in these tumors in response to aberrant DNA damage signal(figure 1). If an upstream regulator of a tumor suppressor is defective, then it is obvious that the whole pathway leading to the induction of tumor suppressor gene will be defective. For example, tumors in which Chk2, an upstream regulator of p53, is mutated, p53 mutations are infrequent.

5. JunB has been shown to be a target gene of $p 73-\alpha[10]$. JunB is a negative regulator of proliferation and it has been shown to induce the transcription of p16 in fibroblasts[11]. Jun $B$ has also been shown to potentiate the function of BRCA1, which is not only expressed in mammary and ovary glands but also in T-cells as well[12] (figure 1). Jun B transgenic mice lost its expression in myeloid lineage resulting in chronic myeloid leukemia, indicating that JunB acts as a tumor suppressor gene in myeloid cells[13]. Silencing of p73 expression by hypermethylation or by any other mechanisms leading to the poor expression of the p73 protein could impair the expression of Jun B in myeloid cells. JunB serves as a causative factor in the development of chronic myeloid leukemia. Both JunB and Jun D are located on human chromosome 19 p13.2, a region that may be involved in chromosomal translocation in acute lymphocytic leukemia (ALL), acute nonlymphocytic leukemia (ANLL) and malignant melanoma (MEL).

6. p16 has been shown to function as a tumor suppressor gene. Further, it has been shown that JunB, a transcriptional target of $\mathrm{p} 73$, potentiates the expression of p16[11] (figure 1). The existence of this pathway is evident from the fact that overexpresssion of p16INK4a correlates with high expression of p73[14]. Furthermore, In a group of 16 patients with acute lymphoplastic leukemia(ALL), p16 was methylated in $11.7 \%$ of patients, and p73 was methylated in $17.6 \%$ of patients. This data highlights the importance of inactivation of p73-JunB-p16 pathway in lymphoplastic leukemia.

7. p57Kip2 is yet another player in the tumor suppressor network. p73-beta has been shown to transactivate p57Kip2 expression[14]. Further it has been shown that p57Kip2 promotes growth arrest in T-cells[15]. p57Kip1 promoter is hypermethylated in a wide variety of lymphoid malignancies. p57KIP2 was found to be frequently methylated (50\%) in acute lymphocytic leukemia (ALL)derived cell lines[16].
8. 14-3-3 sigma has been shown to be a transcriptional target of p53 and p73 and regulates G2/M phase[17]. It has been shown that diminished or decreased expression of 14-3-3 sigma results in increased chemoresistance of cancer cells[18]. Further, 14-3-3 sigma blocks Akt-mediated degradation of p27Kip2 and thereby enhancing the stability of the cell cycle inhibitor p27. Thus, p73, by potentiating the expression of 14-3-3 sigma, increases the chemosensitvity of drug resistant cancer cells[19]. 14-3-3 is hypermethylated in breast cancer(24 of 25 carcinomas (96\%), 15 of 18 (83\%) of ductal carcinoma), 89\% (17/ $19)$ of the HCC and 26 of 60 (43\%) of gastric cancers [2023].

9. BRCA1 appears to be a selective co-activator of 14-3-3 sigma gene transcription[24].

10. Both low E2F-1 expression and p16INK4A inactivation have been identified as independent prognostic markers[23]. This data support a role of E2F-1 as tumor suppressor gene in lymphoma and strongly suggest that the RB1 and p53 pathways are important in the development of de novo diffuse large B cell lymphoma[25].

11. More recent studies implicate p73 in TCR activationinduced cell death (TCR-AICD), indicating that p73-alpha could play a tumor suppressor role in T-cells[26]. p73 has been found to be transcriptionally silenced in some lymphoblastic leukemias and lymphomas due to hypermethylation $[27,28]$.

12. JunB, a transcriptional target of $\mathrm{p} 73$, which functions as a tumor suppressor in myeloid cells, has been shown to be induced by 13.4 fold in Dnmt1\%-fibroblasts, indicating that DNMT can actively silence the expression of JunB when it is expressed[29] (figure 2). DNMT-1 is also shown to be a transcriptional target of c-Jun and $\mathrm{Rb}[30]$. In addition, it has been shown that DNMT-1 specifically targets E2F1-1 element containing promoters and p73 promoter bears E2F1 responsive elements[31]. Evidently, DNMT1s were substantially overexpressed in leukemia cells in a leukemia type-and stage-specific manner. Up-regulated DNMTs may contribute to the pathogenesis of leukemia by inducing aberrant regional hypermethylation of tumor suppressor genes such as p73, JunB, p16, p57kip2, 14-3-3 and BRCA-1.

13. c-Jun has been shown to be activated in Hodgkin's lymphoma and anaplastic large-cell-lymphoma cell lines[32]. AP-1 complex largely contain c-JUN. NFkappa B is also constitutively activated in Hodgkin's lymphoma cells. It could be that overexpressed c-Jun(AP-1 complex) consistently silent p73 by turning on DNA methyl transfereases(DNMT-1) and thereby it could contribute for the development of lymphomas(figure 2). These data further 


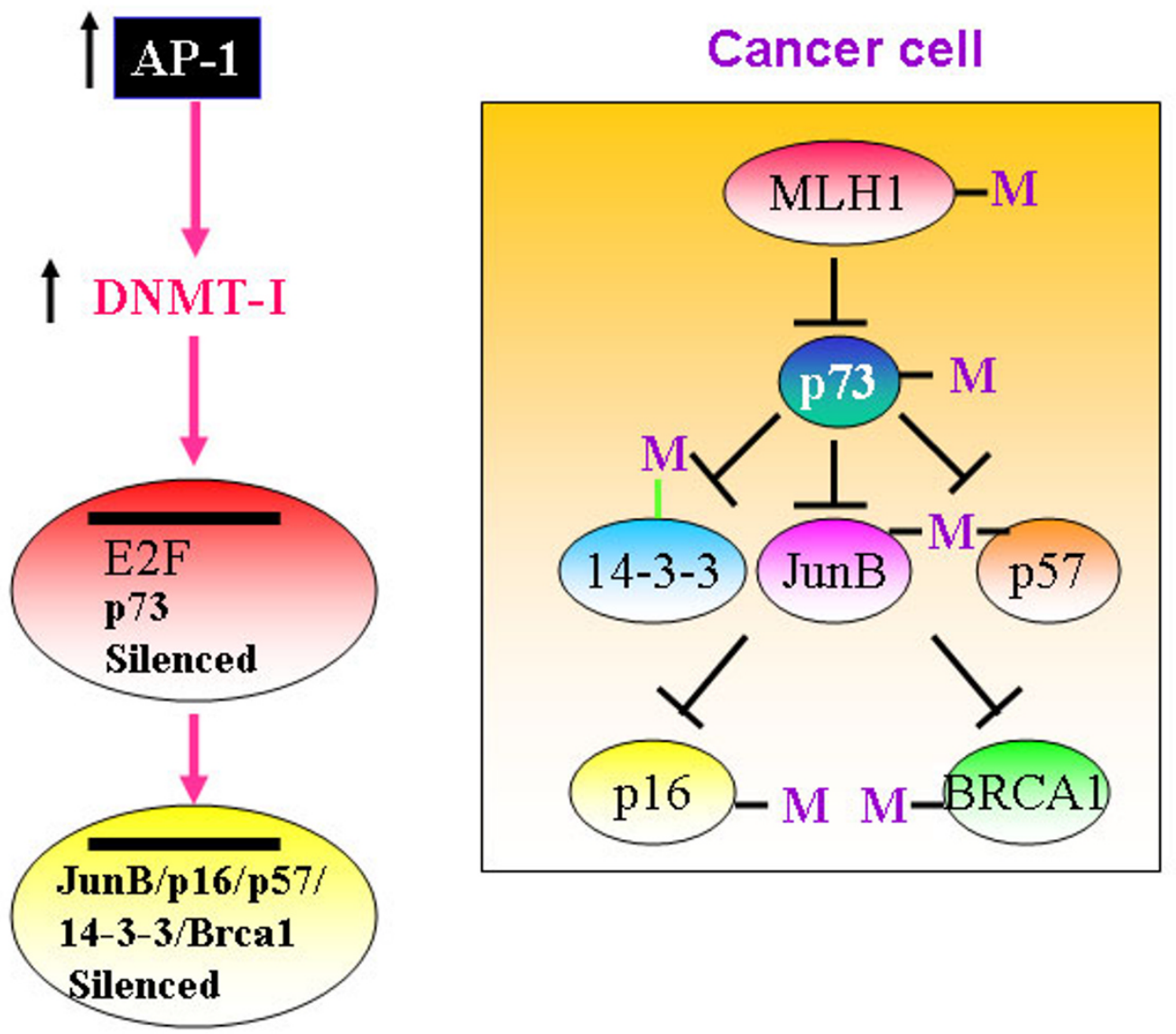

Figure 2

Increased AP-I activity will upregulate DNMT-I levels and thereby silence E2F-I, p73, JunB, pI6, p57, I4-3-3 and BRCA-I expression.

suggest that p73 could behave like a tumor suppressor gene in Non-hodgkin lymphoma and in NK cell lymphoma's. p73 inactivation may be involved in the pathogenesis of both T- and B-ALLs, and that hypermethylation is the predominant mechanism of inactivation of the p73 gene in ALL. Together, it appears that overexpressed AP-1 could silence p73 in lymphocytes.

14. p73 is shown to be a transcriptional target of E2F1[47]. Remarkably, E2F-1 null mice develop unusual spectrum of tumors, indicating that E2F-1 could behave like a tumor suppressor gene. Perhaps, E2F-1 may induce p73 expression to prevent tumorigenesis. Interestingly, E2F-1 null mice develop spelenomegaly and are resistant to apoptosis. Moreover, splenic T-cells isolated from p73deficient mice are resistant to apoptosis induced by the ligation of the T-cell receptors, suggesting that p73 can also induce apoptosis in activated lymphocytes[26].

15. Overexpression of $\mathrm{p} 73$ has been shown to upregulate the expression of several DNA repair proteins including DNA-PK[33]. DNA-PKcs null mice demonstrate complete penetrance of thymic lymphoblastic lymphomas, strongly suggesting that DNAPK functions in mice as a T-cell tumour suppressor. Thus, down regulation of p73 could down regulate DNAPK expression and thereby predispose mice to thymic lymphoma formation.

16. CCAAT/enhancer binding proteins c/EBPs-alpha has been shown to be critical for both early myeloid commitment and terminal granulocyte differentiation. Both p73 and cEBP-alpha share PPXY motif, raising a possibility 
that both, in principle, could be regulated by a common WW domain containing co-activators such as TAZ or YAP to regulate myeloid or granulocite differentiation.

17. p73 has been shown to upregulate the expression of JEM-1, which is down regulated in acute promyelocytic leukemia[34].

18. NAD(P)H:quinone oxidoreductase 1 (NQO1) seems to stabilize both p53 and p73, inhibition of which reduces the levels of p53 and p73. Interestingly, disruption of the NQO1 gene in mice causes myelogenous hyperplasia[35], indicating the absence of p73 could possibly help develop myelogenous hyperplasia.

19. Promyeolocytic leukemia(PML) has been identified as one of the interacting proteins of $\mathrm{p} 73$ through the yeast two hybrid systems[36]. Further, PML has been shown to increase the stability and function of p73[37]. Retroviral expression of beta-catenin, plakoglobin, or PML suppressed the tumorigenicity of p53-negative human renal carcinoma cells, thus pointing to a novel antioncogenic response triggered by catenins that is mediated by the induction of PML.

\section{If indeed p73 is a tumor suppressor gene, then why p73 null mice failed to develop lymphoma? Explanation I}

It has been shown that adenosine deaminase (ADA) is a transcriptional target of p73 and p63[38,39]. Further, it has been shown that decreased expression of ADA could lead to increased levels of adenosine. In fact, it has been shown that ADA deficiency could lead to thymic apoptosis and defective TCR signaling. Hence, I hypothesize that p73 null mice will have high level of adenosine accumulated at various sites due to low expression of adenosine deaminase (ADA). If $\mathrm{p} 73$ and $\mathrm{p} 63$ are positive regulators of ADA, then ADA expression will be decreased in p73/ p63 null mice that could result in increased adenosine level in p73/p63 null mice (figure 3). It has been shown that both adenosine and its agonists inhibit the growth of various tumor cell types such as melanoma, colon or prostate carcinoma and lymphoma [40-42]. This effect is specific and is exerted on tumor cells only. Increased adenosine level could:(a) Prevent initiation/formation of tumors by interfering with protein and RNA biosynthesis and thereby inhibit proliferation. In support of this hypothesis, the generalized suppression of growth is evident in p73 null mice. This could be due to increased extra and intra cellular levels of adenosine, as increased adenosine could inhibit the protein and RNA synthesis and thereby prevent tumor formation(figure 3). (b) Prevent lymphoma formation. (c) Potentiate the function of adenosine $3 a$ receptor, which provides anti-proliferative

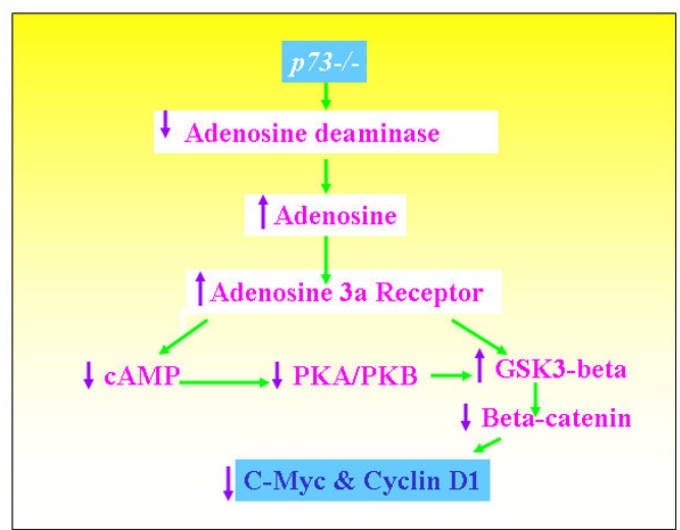

\section{Figure 3}

Increased adenosine concentration down regulates various proliferation regulating mechanisms.

signals[41]. Together, this explains why p73 null mice failed to develop lymphoma.

\section{Explanation 2}

What I intend to propose here is that p73 may not be a primary tumor suppressor gene, like its counter part p53, but it looks certain that it is a participant in the tumor suppressor network. The $\mathrm{p} 73$ promoter is strongly activated in cells expressing exogenous E2F1 and suppressed by exogenous Rb. E2F1 null mice develop various tumors including lymphoma. This might suggest that E2F1 could exert its anti-proliferative action via p73. In addition, E2F1 is capable of activating p19ARF and thereby it can increase the stability of $\mathrm{p} 53$ protein to control proliferation(figure 4). This is to say that, in the absence of p73, E2F could still control aberrant proliferation by turning on p19/ARF and thereby stabilizing p53. In the absence of p73 and p63, p53 is still capable of eliciting growth arrest - but not apoptosis - by transactivating p21 promoter[43]. This also explains why p73 null mice failed to develop lymphoma. The absence of E2F-1 affects both p53 stability and p73 expression and ARF/p19 expression. This explains why E2F1\% null mice develop tumors, unlike p73 null mice.

\section{Explanation 3}

The tumor suppressor pathway in which p73 appears to be a participant involves E2F1, JunB, p16, p19, p57kip2 and BRCA1 (figure 4). Each of which can elicit anti-proliferative effect on its own and in the absence of the other. In the absence of p73, Jun B transcription could still be transactivated by other factors. And JunB could still be capable of transactivating p16 expression and augment the function of BRCA1. Further, if p73 functions like its 


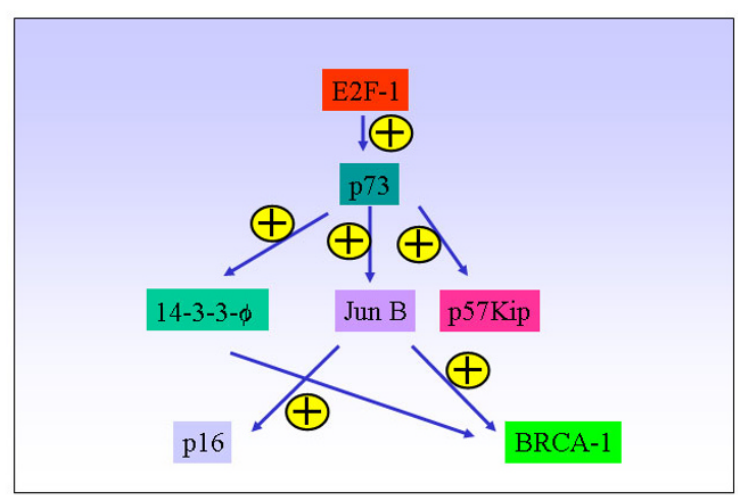

\section{Figure 4}

E2F-I-p73 tumor suppressor network.

dictator, E2F-1, then we should have seen lymphoma in p73 null mice, but that is not the case. This can be explained if one considers the fact that E2F-1 tumor suppressor pathway or network, seems to control the expression and the stability of various tumor suppressor genes such as p19ARF, p53, JunB, p16, BRCA, p57Kip2 etc., in addition to p73(figure 4).

\section{Explanation 4}

The facts that TA-p73 can induce apoptosis and it is hypermethylated in tumors of lymphoid origin indicate that this could function like a tumor suppressor gene. On the other hand, accumulating evidence suggest that deltaNp73 functions more like an oncogene $[44,45]$. Cancer is a genetic disease that arises through inactivation of tumor suppressor genes and activation of oncogenes. Removal of both oncogene and tumorsuppressor gene may not lead to spontaneous tumor formation. For example, this could be analogous to a situation where removal of both p27Kip2 (inhibitor of proliferation) and cyclin D1 (activator of proliferation) may not lead to tumor formation. Interestingly, p73 null mice lack both TA-p73 and deltaNp73, perhaps this could be the reason why p73 null mice do not develop spontaneous tumors. In fact, it appears that p73 null fibroblasts proliferate slowly(Antonio et al., personal communication).

Considering these facts presented here one would not be surprised by the fact that why p $73 \%$ mice failed to develop lymphoma, unlike p53 null mice.

Why do p73 mutations are infrequent in tumors? 1. p73 gene contains several alternative spliced forms, which vary in their ability to elicit growth suppressor response. This flexibility in function will be added factor for modulation, rather than complete inactivation. Thus, just by varying the expression of p73 splicing products(TAp73 Vs DN-p73) it can be finely regulated.

2. p73 promoter is rich in $\mathrm{CpG}$ rich islands, unlike p53 promoter. Thus, p73 is subject to methylation mechanisms mediated inactivation rather than point mutations.

3. p73 appears to co-operate with several proto-oncogenes such as, ras, E2F-1, cyclins (A-E), BCR-abl, and myc, therefore, it could be less prone to selection pressure for point mutations unlike p53. Both p53 and p73 seem to share upstream components especially in response to DNA damaging drugs. p53 is mutated or its upstream/downstream component is altered in $80 \%$ of cancer cells. If upstream component is altered then it may not be able to activate p73-mediated apoptotic pathway, so it may not perform its function effectively. MLH-1 is shown to be an upstream regulator of p73, unlike p53. MLH-1 is hypermethylated in a wide variety of tumors. Thus, in the absence of MLH-1 expression, p73 may not be activated and respond to DNA damage signals.

4. In-vitro studies support the view that E2F1 is overexpressed in various cell lines and it regulates proliferation, while invivo studies suggest that it is a tumor suppressor gene. Although knock-out studies in mice suggest that E2F-1 functions as a tumor suppressor, until now no mutation has been reported in human tumors. This could be due to the fact that complete inactivation of E2F1 function may be deleterious to the survival of normal/ cancer cells, as E2F1 also regulates proliferation associated genes. So, it is prudent not to anticipate any mutations in E2F1 gene. Similarly, p73 being a direct transcriptional target of E2F-1, it could be part of the regulatory mechanisms that control proliferation signals as well. Moreover, p73 could act as an anti-apoptotic and a pro-apoptotic protein, depending upon the cellular context and expression pattern of p73 isoforms. Thus, p73 mutations are infrequent.

E2F1-deficient mice have been shown to develop various tumors including reproductive tract sarcomas, lymphoma and lung adenocarcinoma, suggesting that it functions as a tumor suppressor gene[46]. Subsequently, it has been shown that JunB, a negative regulator of proliferation, is a potential transcriptional target of the tumor suppressor p53 homolog, p73 [9,47]. Furthermore, p73 has been shown to be a transcriptional target of the tumor suppressor gene, E2F1[48] (figure 5). Wild-type mouse embryonic fibroblasts showed $77 \%$ apoptosis after forced E2F1 expression, both $p 53 \%$ MEFs(expressing wild-type p73) and $p 73 \%$ MEFs (expressing wild-type p53), showed reduced apoptotic cell death after forced E2F1 expression with $12 \%$ and $15 \%$ respectively[48]. The inability of $p 73-1$ 


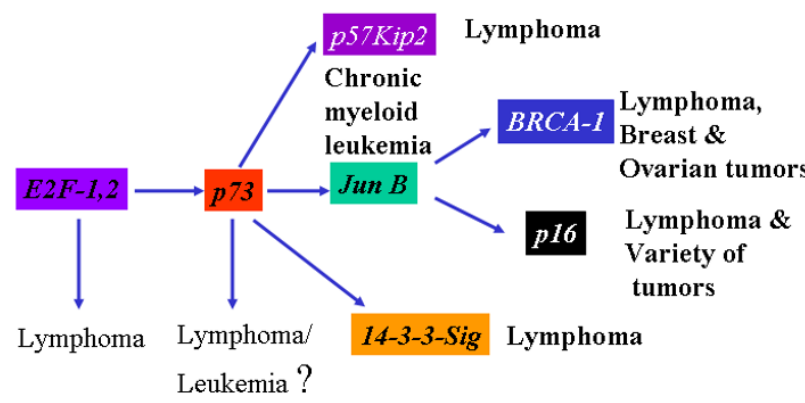

Figure 5

Knock out of each gene in E2F-I-p73 network of proteins result in lymphoma formation.

- mouse embryonic fibroblasts cells to undergo, despite the presence of wtp53, apoptosis indicate that synergistic but independent activation signal stemming from TAp73 that co-operate with p53 to induce E2F1-triggered cell death[48]. These findings strongly suggest that E2F1 could exert its tumor suppressor function, at least in part, via p73. In support of this notion, Zhu JW et al., [49] showed that $E 2 \mathrm{~F}^{-}-E 2 \mathrm{~F} 2^{+/-}$or $E 2 \mathrm{~F} 1^{-/+E} 2 \mathrm{~F} 2^{-/}$mice developed various tumors including T/B-cell-lymphomas, lung tumors and myeloid hyperplasia/leukemia. Accordingly, JunB - a transcriptional target of p73 - null mice develop chronic myeloid leukemia(CML) like disease ref. 12(figure 5), suggesting that JunB functions as p73's downstream target and it functions as a tumor suppressor gene in mice. In line with this data, it has further been shown that JunB expression is silenced in CML by hypermethylation[50] and it functions as a negative regulator of B-lymphoid proliferation[51] However, on the contrary to the expectation, p73 null mice failed to develop spontaneous lymphoma formation even after two years[52]. By contrast, p73 is hypermethylated in various tumors. How can we explain this tumor paradox? It is plausible that spontaneous tumor formation in p73 null mice could be prevented by a molecule(s), such as adenosine, produced in its absence.

\section{References}

I. Siu LL, Chan JK, Wong KF, Kwong YL: Specific patterns of gene methylation in natural killer cell lymphomas: $p 73$ is consistently involved. Am J Pathol 2002, I60(1):59-66.

2. Siu LL, Chan JK, Wong KF, Choy C, Kwong YL: Aberrant promoter CpG methylation as a molecular marker for disease monitoring in natural killer cell lymphomas. $\mathrm{Br} J$ Haematol 2003, I 22(I):70-7.

3. Kawamata N, Inagaki N, Mizumura S, Sugimoto KJ, Sakajiri S, Ohyanagi-Hara M, Oshimi K: Methylation status analysis of cell cycle regulatory genes (pI6INK4A, pI5INK4B, p2IWafI/CipI,
p27Kip I and p73) in natural killer cell disorders. Eur J Haematol 2005, 74(5):424-9.

4. Melino G, De Laurenzi V, Vousden KH: p73: Friend or foe in tumorigenesis. Nat Rev Cancer 2002, 8:605-I5.

5. Sayan AE, Rossi M, Melino G, Knight RA: p73: in silico evidence for a putative third promoter region. Biochem Biophys Res Commun 2004, 3 I 3(3):765-70.

6. Rodicker F, Stiewe T, Zimmermann S, Putzer BM: Therapeutic efficacy of E2FI in pancreatic cancer correlates with TP73 induction. Cancer Res 200I, 6 I(19):7052-5.

7. House MG, Guo M, lacobuzio-Donahue C, Herman JG: Molecular progression of promoter methylation in intraductal papillary mucinous neoplasms (IPMN) of the pancreas. Carcinogenesis 2003, 24(2): 193-8.

8. Gong JG, Costanzo A, Yang HQ, Melino G, Kaelin WG Jr, Levrero M, Wang JY: The tyrosine kinase c-Abl regulates $\mathrm{p} 73$ in apoptotic response to cisplatin-induced DNA damage. Nature 1999, 399(6738):806-9.

9. Yu J, Zhang L, Hwang PM, Rago C, Kinzler KW, Vogelstein B: Identification and classification of p53-regulated genes. Proc Natl Acad Sci USA 1999, 96(25): 14517-22.

10. Passegue $E$, Wagner EF: JunB suppresses cell proliferation by transcriptional activation of p I 6(INK4a) expression. EMBO J 2000, 19 (I 2):2969-79.

II. Hu YF, Li R: JunB potentiates function of BRCAl activation domain I (ADI) through a coiled-coil-mediated interaction. Genes Dev 2002, I 6(12): I509-17.

12. Passegue E, Jochum W, Schorpp-Kistner M, Mohle-Steinlein U, Wagner EF: Chronic myeloid leukemia with increased granulocyte progenitors in mice lacking junB expression in the myeloid lineage. Cell 200I, I04(I):2I-32.

13. Garcia V, Silva J, Dominguez G, Garcia JM, Pena C, Rodriguez R, Provencio $M$, Espana $P$, Bonilla F: Overexpression of pI6INK4a correlates with high expression of p73 in breast carcinomas. Mutat Res 2004, 554: I-2.

14. Vaccarello G, Figliola R, Cramerotti S, Novelli F, Maione R: p57Kip2 is induced by MyoD through a p73-dependent pathway. J Mol Biol 2006, 356(3):578-88.

15. Li G, Domenico J, Lucas JJ, Gelfand EW: Identification of multiple cell cycle regulatory functions of p57Kip2 in human T lymphocytes. J Immunol 2004, 173(4):2383-91.

16. Shen L, Toyota M, Kondo Y, Obata T, Daniel S, Pierce S, Imai K, Kantarjian HM, Issa JP, Garcia-Manero G: Aberrant DNA methylation of p57KIP2 identifies a cell-cycle regulatory pathway with prognostic impact in adult acute lymphocytic leukemia. Blood 2003, $101(10): 4131-6$.

17. Yang HY, Wen YY, Chen CH, Lozano G, Lee MH: 14-3-3 sigma positively regulates $\mathrm{p} 53$ and suppresses tumor growth. Mol Cell Biol 2003, 20:7096-107.

18. Sang M, Li Y, Ozaki T, Ono S, Ando K, Yamamoto H, Koda T, Geng C, Nakagawara A: p73-dependent induction of 14-3-3 sigma increases the chemo-sensitivity of drug-resistant human breast cancers. Biochem Biophys Res Commun 2006, 347(I):327-33.

19. Yang H, Zhang Y, Zhao R, Wen YY, Fournier K, Wu HB, Yang HY, Diaz J, Laronga C, Lee MH: Negative cell cycle regulator 14-3-3 sigma stabilizes p27 Kip I by inhibiting the activity of PKB/ Akt. Oncogene 2006, 25(33):4585-94.

20. Umbricht CB, Evron E, Gabrielson E, Ferguson A, Marks J, Sukumar $S$ : Hypermethylation of 14-3-3 sigma (stratifin) is an early event in breast cancer. Oncogene 200I, 20(26):3348-53.

21. Iwata N, Yamamoto H, Sasaki S, Itoh F, Suzuki H, Kikuchi T, Kaneto H, Iku S, Ozeki I, Karino Y, Satoh T, Toyota J, Satoh M, Endo T, Imai $\mathrm{K}$ : Frequent hypermethylation of CpG islands and loss of expression of the 14-3-3 sigma gene in human hepatocellular carcinoma. Oncogene 2000, 19(46):5298-302.

22. Suzuki H, Itoh F, Toyota M, Kikuchi T, Kakiuchi H, Imai K: Inactivation of the 14-3-3 sigma gene is associated with 5 ' CpG island hypermethylation in human cancers. Cancer Res 2000, 60(16):4353-7.

23. Ferguson AT, Evron E, Umbricht CB, Pandita TK, Chan TA, Hermeking $\mathrm{H}$, Marks JR, Lambers AR, Futreal PA, Stampfer MR, Sukumar S: High frequency of hypermethylation at the 14-3-3 sigma locus leads to gene silencing in breast cancer. Proc Natl Acad Sci USA 2000, 97 (II):6049-54. 
24. Aprelikova O, Pace AJ, Fang B, Koller BH, Liu ET: BRCAI is a selective co-activator of 14-3-3 sigma gene transcription in mouse embryonic stem cells. J Biol Chem 200I, 276(28):25647-50.

25. Moller MB, Kania PW, Ino Y, Gerdes AM, Nielsen O, Louis DN, Skjodt K, Pedersen NT: Frequent disruption of the RB I pathway in diffuse large $B$ cell lymphoma: prognostic significance of E2F-I and p I 6INK4A. Leukemia 2000, I 4(5):898-904.

26. Lissy NA, Davis PK, Irwin M, Kaelin WG, Dowdy SF: A common E2F-I and p73 pathway mediates cell death induced by TCR activation. Nature 2000, 407(6804):642-5.

27. Corn PG, Kuerbitz SJ, van Noesel MM, Esteller M, Compitello N, Baylin SB, Herman JG: Transcriptional silencing of the p73 gene in acute lymphoblastic leukemia and Burkitt's lymphoma is associated with 5' CpG island methylation. Cancer Res 1999, 59(I4):3352-6.

28. Kawano S, Miller CW, Gombart AF, Bartram CR, Matsuo Y, Asou H, Sakashita A, Said J, Tatsumi E, Koeffler HP: Loss of p73 gene expression in leukemias/lymphomas due to hypermethylation. Blood 1999, 94(3): I I I3-20.

29. Rhee I, Bachman KE, Park BH, Jair KW, Yen RW, Schuebel KE, Cui H, Feinberg AP, Lengauer C, Kinzler KW, Baylin SB, Vogelstein B: DNMTI and DNMT3b cooperate to silence genes in human cancer cells. Nature 2002, 4 I 6(6880):552-6.

30. Slack A, Pinard M, Araujo FD, Szyf M: A novel regulatory element in the dnmt l gene that responds to co-activation by $R b$ and c-Jun. Gene 200I, 268(I-2):87-96.

31. Robertson KD, Ait-Si-Ali S, Yokochi T, Wade PA, Jones PL, Wolffe AP: DNMTI forms a complex with Rb, E2FI and HDACI and represses transcription from E2F-responsive promoters. Nat Genet 2000, 25(3):338-42.

32. Mathas S, Hinz M, Anagnostopoulos I, Krappmann D, Lietz A, Jundt F, Bommert K, Mechta-Grigoriou F, Stein H, Dorken B, Scheidereit C: Aberrantly expressd $c$-Jun and JunB are a hallmark of Hodgkin lymphoma cells, stimulate proliferation and synergize with NF-kappa B. EMBO J 2002, 2 I (I 5):4 I04- I 3.

33. Vikhanskaya F, Marchini S, Marabese M, Galliera E, Broggini M: p73a overexpression is associated with resistance to treatment with DNA-damaging agents in a human ovarian cancer cell line. Cancer Res 200I, 6 I (3):935-8.

34. Tong JH, Fant X, Duprez E, Benoit G, Uphoff CC, Drexler HG, Pla JC, Lofvenberg E, Lanotte M: Expression patterns of the JEM-I gene in normal and tumor cells: ubiquity contrasting with a faint, but retinoid-induced, $m$ RNA expression in promyelocytic NB4 cells. Leukemia I998, I 2(I I): I733-40.

35. Long DJ 2nd, Gaikwad A, Multani A, Pathak S, Montgomery CA, Gonzalez FJ, Jaiswal AK: Disruption of the NAD(P)H:quinone oxidoreductase I (NQOI) gene in mice causes myelogenous hyperplasia. Cancer Res 2002, 62(I I):3030-6.

36. Minty A, Dumont $X$, Kaghad M, Caput D: Two-hybrid screening with p73 identifies novel SUMO-I-interacting proteins and a SUMO-I interaction motif. J Biol Chem 2000, 275(46):363 I6-23.

37. Bernassola F, Salomoni P, Oberst A, Di Como CJ, Pagano M, Melino G, Pandolfi PP: Ubiquitin-dependent degradation of p73 is inhibited by PML. J Exp Med 2004, I 99( I I): I 545-57.

38. Tullo A, Mastropasqua G, Bourdon JC, Centonze P, Gostissa M, Costanzo A, Levrero M, Del Sal G, Saccone C, Sbisa E: Adenosine deaminase, a key enzyme in DNA precursors control, is a new p73 target. Oncogene 2003, 22(54):8738-48.

39. Sbisa E, Mastropasqua G, Lefkimmiatis K, Caratozzolo MF, D'Erchia AM, Tullo A: Connecting p63 to cellular proliferation: the example of the adenosine deaminase target gene. Cell Cycle 2006, 5(2):205-12.

40. Extracellular: ATP induces apoptotic signaling in human monocyte leukemic cells, HL-60 and F-36P. Arch Pharm Res 2006, 29(I I): I032-4I.

41. Wen LT, Knowles AF: Extracellular ATP and adenosine induce cell apoptosis of human hepatoma $\mathrm{Li}-7 \mathrm{~A}$, cells via the $\mathrm{A} 3$ adenosine receptor. Br J Pharmacol 2003, I40(6): I 009-I8.

42. Fishman P, Bar-Yehuda S, Ohana G, Pathak S, Wasserman L, Barer F, Multani AS: Adenosine acts as an inhibitor of lymphoma cell growth: a major role for the $\mathbf{A} 3$ adenosine receptor. Eur J Cancer 2000, 36(I I): |452-8.

43. Flores ER, Tsai KY, Crowley D, Sengupta S, Yang A, McKeon F, Jacks $T:$ p63 and p73 are required for p53-dependent apoptosis in response to DNA damage. Nature 2002, 41 6(6880):560-4.
44. Stiewe T, Zimmermann S, Frilling A, Esche H, Putzer BM: Transactivation-deficient DeltaTA-p73 acts as an oncogene. Cancer Res 2002, 62(13):3598-602.

45. Stiewe T, Putzer BM: Role of p73 in malignancy: tumor suppressor or oncogene? Cell Death Differ 2002, 9(3):237-45.

46. Yamasaki L, Jacks T, Bronson R, Goillot E, Harlow E, Dyson NJ: Tumor induction and tissue atrophy in mice lacking E2F-I. Cell 1996, 85(4):537-48.

47. Castellazzi M, Spyrou G, La Vista N, Dangy JP, Piu F, Yaniv M, Brun G: Overexpression of $c$-jun, junB, or junD affects cell growth differently. Proc Natl Acad Sci USA I991, 88(20):8890-4.

48. Irwin M, Marin MC, Phillips AC, Seelan RS, Smith DI, Liu W, Flores ER, Tsai KY, Jacks T, Vousden KH, Kaelin WG Jr: Role for the p53 homologue p73 in E2F-I-induced apoptosis. Nature 2000, 407(6804):645-8.

49. Zhu JW, Field SJ, Gore L, Thompson M, Yang H, Fujiwara Y, Cardiff RD, Greenberg M, Orkin SH, DeGregori J: E2FI and E2F2 determine thresholds for antigen-induced $\mathrm{T}$-cell proliferation and suppress tumorigenesis. Mol Cell Biol 200I, 2 I (24):8547-64.

50. Yang MY, Liu TC, Chang JG, Lin PM, Lin SF: JunB gene expression is inactivated by methylation in chronic myeloid leukemia. Blood 2003, I 0 I(8):3205-II.

5I. Szremska AP, Kenner L, Weisz E, Ott RG, Passegue E, Artwohl M, Freissmuth M, Stoxreiter R, Theussl HC, Parzer SB, Moriggl R, Wagner EF, Sexl V: JunB inhibits proliferation and transformation in B-lymphoid cells. Blood 2003, I 02(I 2):4I59-65.

52. Yang A, Walker N, Bronson R, Kaghad M, Oosterwegel M, Bonnin J, Vagner C, Bonnet H, Dikkes P, Sharpe A, McKeon F, Caput D: p73deficient mice have neurological, pheromonal and inflammatory defects but lack spontaneous tumours. Nature 2000, 404(6773):99-103.
Publish with Bio Med Central and every scientist can read your work free of charge

"BioMed Central will be the most significant development for disseminating the results of biomedical research in our lifetime."

Sir Paul Nurse, Cancer Research UK

Your research papers will be:

- available free of charge to the entire biomedical community

- peer reviewed and published immediately upon acceptance

- cited in PubMed and archived on PubMed Central

- yours - you keep the copyright

Submit your manuscript here:

http://www.biomedcentral.com/info/publishing_adv.asp
BioMedcentral 